Carlos Huneeus, La democracia semisoberana. Chile después de Pinochet (Santiago: Taurus, 2014).

RESEÑA

\title{
¿UN CHILE SEMISOBERANO?
}

\author{
Agustín Squella \\ Universidad de Valparaiso
}

\footnotetext{
$\mathrm{P}$
} odemos llamar "transición a la democracia" al proceso por el cual se pasa de un régimen no democrático de gobierno, generalmente una dictadura, a uno de carácter democrático.

Chile tuvo su transición a la democracia, un proceso que empezó con el plebiscito de 1988 y siguió con las primeras reformas pactadas a la Constitución de 1980 — que tuvieron lugar en 1989- y el ejercicio de los poderes ejecutivo y legislativo por representantes electos por sufragio universal, hecho, este último, que acaeció el 11 de marzo de 1990. Con todo, en el caso chileno, al menos hasta el momento que acabamos de señalar, lo que hubo no fue el paso de una dictadura militar a una democracia, sino el paso de una dictadura a la democracia protegida que consagró la Constitución de 1980, una democracia groseramente limitada a favor de la ideología política, económica, social y cultural que fue plasmada en ese texto y a favor de las fuerzas políticas que apoyaron el régimen militar, que, como era previsible, no iban a contar con las preferencias de los ciudadanos una vez que éstos empezaran a participar en las elecciones presidenciales y parlamentarias. La frenética dictación de leyes orgánicas constitucionales antes del 11 de marzo de 1990 - ése sí que fue un verdadero frenesí legislativo_, leyes que tienen un alto quórum para su aprobación, modificación y derogación; la 
mantención del quórum de dos tercios de los senadores y diputados en ejercicio para reformar los capítulos más importantes de la Constitución a partir de 1990, con un Senado, además, que a partir de ese año y hasta 2005 no fue elegido por votación popular en el 20 por ciento de sus integrantes; y todo eso con el general Pinochet a cargo siempre del Ejército durante los primeros años de la transición, y más tarde con asiento como senador vitalicio en el Senado: he ahí algunos de los hechos que pusieron freno al proceso iniciado en 1988.

Cómo no mencionar, asimismo, un sistema binominal para elegir senadores y diputados — cambiado recién el año 2015 para regir por primera vez en elecciones parlamentarias que tendrán lugar en 2017-, que aseguró a ambas coaliciones mayoritarias una representación más o menos similar tanto en la Cámara de Diputados como en el Senado. Según quienes la idearon, esta figura garantizó equilibrio durante más de un cuarto de siglo, aunque al precio inaceptable de obstruir deliberadamente la aplicación de la regla de la mayoría, de obstaculizar que candidatos independientes o nuevas fuerzas políticas emergentes pudieran asomarse siquiera al Congreso Nacional, y de debilitar seriamente el carácter representativo del Congreso durante 27 años.

Todavía más: figuras políticas civiles que dieron sustento al régimen militar durante los 17 años, y que trabajaron activamente para éste - tiempo durante el cual hicieron fuertes y hasta majaderas críticas a los partidos políticos y a la democracia como forma de gobierno-, una vez terminado ese régimen corrieron a formar partidos y a inscribir sus candidaturas para postular a los asientos que en ambas cámaras les permitieran proteger durante el mayor tiempo posible el legado de Pinochet, del cual la Constitución de 1980 era su pieza mayor.

Así las cosas, en 1990 lo que fue recuperado fue una democracia fuertemente limitada y desde ese momento, aunque con exasperante lentitud, se empezó a caminar hacia una democracia plena o, cuando menos, hacia una democracia digna de ese nombre y de ocupar un lugar decente en el ranking de las democracias de finales del siglo XX.

En consecuencia, tuvimos una transición de dos tiempos: de la dictadura a la democracia protegida y fuertemente limitada que se recuperó en 1990, y desde ésta a un régimen de democracia plena, y si bien podría darse por terminado el segundo de ellos en 2005, momento en el que fueron aprobadas las principales reformas a la Constitución 
de 1980, políticos y politólogos continúan discutiendo si la transición chilena a la democracia está o no terminada y, en caso de estarlo, a partir de qué momento. Según mi parecer, difícilmente esa transición podría darse por concluida si a las fuerzas políticas defensoras de la Constitución de 1980 les basta un tercio más un voto en ambas cámaras del Congreso Nacional para impedir la aprobación de cualquier reforma constitucional, ni qué decir para aprobar una eventual nueva Constitución. Puesto que si bien han sido aprobadas un buen número de reformas a la Constitución de 1980, aquellas que tenían que ver con los enclaves más fuertemente autoritarios de esa carta fundamental recién pudieron hacerse el año 2005. Hasta ese año existieron los senadores designados y vitalicios, hasta ese año subsistió el Consejo de Seguridad Nacional (Cosena) según el texto primitivo de la Constitución de 1980 y hasta ese año el Presidente de la República no tuvo la facultad de remover de su cargo al Comandante en Jefe de las Fuerzas Armadas, algo que atentaba contra la subordinación del poder militar al poder político, que es propia de toda democracia digna de este nombre.

Por otra parte, algo que ha confundido no poco a nuestra peculiar y perezosa transición, bajo mi punto de vista, ha sido el discurso de la reconciliación que se instaló en el país luego del plebiscito de 1988 y que en alguna medida pervive hasta hoy. Reconciliación no es lo mismo que transición, y bien pudimos haber apurado ésta sin conseguir cabalmente aquélla. La transición es un proceso político, jurídico, institucional, mientras que la reconciliación designa un proceso de tipo espiritual, o cultural si se prefiere, para restar a este proceso la connotación religiosa que podría otorgarle la palabra "espiritual". A ese proceso de reconciliación se le dio demasiada importancia, como si no se pudiera avanzar rápidamente en la transición mientras los chilenos no volvieran a mirarse nuevamente como hermanos, una ilusión, esta última, que no cabe formarse ni siquiera en países que no han tenido golpes de Estado ni prolongadas dictaduras

Según mi manera de ver las cosas, a la reconciliación habría que dejarla seguir su curso, puesto que la índole de un proceso de ese tipo pasa antes por cambios generacionales que por decisiones normativas o modificaciones institucionales.

El último libro de Carlos Huneeus, La democracia semisoberana. Chile después de Pinochet, es un muy estimable resultado de la 
extensa y cuidada investigación llevada a cabo por su autor en el curso de los últimos años. El libro terminó de escribirse en el invierno de 2014 y va a constituirse en una fuente de consulta indispensable para completar la visión que pueda tenerse acerca de lo ocurrido en Chile, especialmente entre 1990 y 2010, es decir, en los cuatro primeros períodos de gobierno de la Concertación de Partidos por la Democracia. En cuanto al título de la obra, lo dice todo, particularmente con la palabra "semisoberana", una expresión técnicamente acertada para describir el tipo de democracia que hemos tenido a partir de 1990. Sí, "semisoberana", porque ese carácter tuvo la democracia recuperada en 1990, y porque todavía hay tareas pendientes a nivel normativo e institucional para que tengamos una democracia en forma, una democracia de la que podamos sentirnos orgullosos o, cuando menos, satisfechos.

En el origen de nuestra democracia semisoberana - señala $\mathrm{Hu}-$ neeus - hay algunos factores que destacar. Primero, la hegemonía de la economía sobre la política y la casi perfecta continuidad de un sistema económico heredado de la dictadura; segundo, la política de los acuerdos, comprensible y en cierto modo inevitable durante los primeros cuatro años de la transición, pero que se prolongó también en exceso, incluso hasta hoy, como si la democracia como forma de gobierno tuviera que terminar todas las discusiones con acuerdos, avergonzándose de los desacuerdos, ni qué decir de los conflictos, y renunciar a la aplicación de la regla de la mayoría; y, tercero, la adopción por los gobiernos de la Concertación de una política de expertos antes que de ciudadanos, con los economistas no sólo sentados a la mesa sino que además a la cabecera de ésta, con el consiguiente debilitamiento de las organizaciones sociales y hasta de los propios partidos políticos. Durante la década final del gobierno militar y buena parte del tiempo que vino después, la hegemonía de los economistas en el gobierno e incluso la supremacía casi sin contrapesos del lenguaje y de las categorías de análisis de la economía constituyeron un fenómeno bastante evidente.

La indiferencia, apatía y por momentos franca desidia de las élites chilenas para superar esos tres aspectos ha durado ya largo tiempo, un fenómeno que el autor de este libro ve también presente con la aprobación de la inscripción automática en los registros electorales (un 
bien) y el fin del voto obligatorio (un mal). Si se quería aumentar la participación política, ya claramente debilitada, lo que debió aprobarse fue la inscripción automática, mas no el voto voluntario, según quedó claramente demostrado en las elecciones presidencial y parlamentarias del año 2013. Pero lo que se hizo fue transformar al país en una suerte de paraíso electoral, puesto que el mensaje enviado a los chilenos, en especial a los jóvenes, fue éste: no se moleste en inscribirse y tampoco en ir a votar el día de las elecciones. ¿Qué deberes principales tienen los ciudadanos de un país, además de cumplir sus leyes, si no es pagar los impuestos y votar en las elecciones populares? Y seamos francos: también hemos sido una suerte de paraíso fiscal, que ha permitido evadir y eludir con suma facilidad los impuestos a las grandes fortunas y a las sociedades de profesionales de altos ingresos constituidas exclusivamente con la finalidad de aliviar la carga fiscal de sus miembros, mientras que los impuestos que deben pagar los trabajadores, además del regresivo IVA, se les descuentan todos los meses por planilla. A propósito de eso, vale la pena recordar lo que disponen los artículos XXXIII y XXXVI de la Declaración Americana de los Derechos y Deberes del Hombre, aprobada el año 1948 en Bogotá: "Toda persona tiene el deber de votar en las elecciones populares del país del que sea nacional"; y "Toda persona tiene el deber de pagar los impuestos establecidos por la ley para el sostenimiento de los servicios públicos".

Entre los inicialmente partidarios del voto voluntario - incluido el autor de este comentario-, no son pocos los que han cambiado su opinión a este respecto. Enhorabuena, aunque se pueden tener fuertes dudas de que nuestros parlamentarios se atreverán a volver al "impopular" voto obligatorio. Sin embargo, nada impide que un derecho - $-\mathrm{y}$ el de sufragio lo es - pueda ser a la vez un deber. Es lo que pasa, por ejemplo, con la instrucción primaria obligatoria. Es lo que ocurre también con el derecho/deber de los estudiantes de asistir a clases en los establecimientos educacionales en los que han sido matriculados. Habría que fijarse en el nombre de la Declaración Americana antes mencionada: "de los Derechos y Deberes del Hombre". Es efectivo que vivimos el tiempo de los derechos, felizmente, pero ello no debe ser motivo para que faltemos a nuestros deberes o los tomemos con liviandad. Sin renunciar para nada a la cultura de los derechos, es preciso reponer en Chile una cultura de los deberes y del esfuerzo individual. 
Con la eliminación del voto obligatorio se impuso una vez más la lógica de los economistas: la "oferta" de los candidatos mejoraría sustancialmente para atraer votantes a las urnas los días de elecciones, una predicción ingenua, que no se cumplió. Por lo demás, los votos nulos o en blanco que aparecen en una elección son fácilmente interpretables (ninguno de los candidatos fue del agrado del respectivo votante), mientras que la abstención, legalizada por la voluntariedad del sufragio, puede atribuirse a motivos múltiples y muy variados. Cuando el voto es obligatorio, los ciudadanos convocados a una elección no están obligados a marcar una preferencia, y su voto nulo o en blanco es una inequívoca señal a los candidatos - y a los partidos de éstos- acerca de que ninguno les ha parecido aceptable, un mensaje mucho más claro $y$ aleccionador tanto para unos como para otros a fin de que en futuras elecciones mejoren sus desempeños.

Concentración de la riqueza y desigualdades excesivas en las oportunidades, en los ingresos y en las condiciones materiales de existencia de las personas es otro de los puntos que Huneeus examina en este libro con suficiente atención y una apropiada información empírica. Las desigualdades que no sólo vulneran el valor de la igualdad —o el de la más blanda "equidad", como prefirió comprometer la Concertación-, sino que lo hace también con la libertad, puesto que ¿qué sentido pueden tener las libertades de conciencia, de pensamiento, de expresión, de reunión, de asociación, de emprendimiento de actividades económicas lícitas para personas y grupos familiares que viven en una prolongada condición de pobreza? Si hubo alguna ligereza en sustituir "igualdad" por "equidad" en el discurso político de una coalición de centroizquierda, la hay todavía más en quitar incluso "equidad" y dejar únicamente "crecimiento", como si este último bastara para que aceptables condiciones de vida se distribuyeran por todo el país y no se concentraran en los cuatro o cinco barrios más ricos de las cuatro o cinco ciudades más importantes del país.

"¿Quién gobierna en un sistema político con grandes desigualdades?” se pregunta Carlos Huneeus (378). ${ }^{1}$ ¿Quién gobierna allí donde existen manifiestas y prolongadas desigualdades en el conocimiento, los

${ }^{1}$ En adelante, la mera numeración entre paréntesis indica la página del libro reseñado: Carlos Huneeus, La democracia semisoberana. Chile después de Pinochet (Santiago: Taurus, 2014). 
ingresos, la riqueza, la posición social, el acceso a la justicia, y la cercanía con la administración local, regional y central de un país? En este punto, el autor del libro concluye que "la desigualdad y la concentración de recursos no fueron enfrentados por los gobiernos concertacionistas de centro-izquierda e incluso aumentaron durante los veinte años de administraciones de la Concertación" (380).

Podría decirse que tanto nuestra transición política como económica han sido lentas, si es que existió alguna vez suficiente convicción y voluntad para pasar de una economía de mercado a una economía social de mercado, y desde un sistema económico desregulado, mal fiscalizado y con penas muchas veces irrisorias para los infractores a uno regido por normas pertinentes, debidamente fiscalizado por organismos públicos con suficientes atribuciones y que contemplara penas efectivas para quienes faltaran gravemente a esas normas.

Es del caso mencionar que el autor de este libro dedica algunas páginas a analizar la influencia de los empresarios en los gobiernos de la Concertación, ejercida, según él señala, a través del Centro de Estudios Públicos (CEP), es decir, la institución a la que pertenece la revista en que se publica este comentario. Según el parecer del autor de este último, es efectivo que el CEP fue un importante interlocutor con el gobierno de Ricardo Lagos y con el primero de los que encabezó Michelle Bachelet, aunque no puede decirse que el papel cumplido por esa institución haya consistido únicamente en la difusión de las ideas neoliberales y el papel protagónico que corresponde a la empresa privada en el desarrollo económico de un país. Participante como conferencista o panelista invitado por el CEP a los encuentros semestrales que la institución organiza para estudiantes universitarios sobre temas de teoría política, cine y literatura, mi apreciación del CEP es más compleja de la que aparece en el libro de Carlos Huneeus.

Por mencionar algunos hechos puntuales a los que Huneeus alude en su libro, creo que la decisión del Presidente Lagos de designar a David Gallagher en el directorio del BancoEstado tuvo que ver con el conocimiento y la confianza recíproca que existe entre ambos y no con la condición de Gallagher como consejero del CEP. Tocante a los encuentros que hubo durante el mandato de ese mismo Presidente entre el grupo de sus asesores que encabezó Ernesto Ottone y directivos e investigadores del CEP, en los que el autor de este comentario participó 
regularmente como asesor cultural de la Presidencia y académico que había sido invitado más de una vez a actividades realizadas por el CEP desde 1980 en adelante, puedo decir que dichos encuentros no tuvieron por objeto que ese centro de estudios adelantara al gobierno de Lagos los resultados de las encuestas de opinión política y económica que lleva a cabo periódicamente en el país. Se trató de reuniones mucho más ricas y diversas acerca de la marcha general del país y de la situación internacional. Por otra parte, resulta tendencioso que Huneeus escriba que "consejeros del CEP constituyeron el núcleo de expositores en el ciclo Conferencias Presidenciales de Humanidades" (542) que organicé en La Moneda durante el gobierno de Lagos. Personas vinculadas al CEP que fueron invitadas a la parte nacional de ese ciclo —en total cuatro de doce: Arturo Fontaine, Óscar Godoy, Patricia Matte y Joaquín Fermandois - lo fueron en atención a su trayectoria y méritos en sus respectivas áreas de trabajo, que van desde la historia a la teoría política, la educación y la poesía. Los otros participantes nacionales en el ciclo de conferencias fueron tan diversos como Carla Cordua, José Joaquín Brunner, Jorge Edwards, Manuel Antonio Garretón, Ricardo Ffrench-Davis, Sonia Montecinos, Carlos Peña y el poeta Gonzalo Rojas. Por último, a la parte internacional del ciclo — la más destacada y vistosa - concurrieron Mario Vargas Llosa, Carlos Fuentes, José Saramago, Claudio Magris, Adela Cortina, Gianni Vattimo, Alain Touraine, Fernando Savater y Manuel Castells, y sería un abuso decir - cosa que Huneeus ciertamente no hace- que la presencia allí de Vargas Llosa se debió a su amistad con el entonces director ejecutivo del CEP, Arturo Fontaine Talavera.

Las tesis conspirativas, tan frecuentes aquí como en cualquier otro país, suelen estrellarse contra una realidad mucho más simple y modesta. Cuando terminé mi trabajo junto al Presidente Lagos luego de aprobarse la ley que creó el Consejo Nacional de la Cultura y las Artes (un trabajo que consistía en coordinar a los organismos gubernamentales de cultura y en apoyar la tramitación de ese proyecto de ley, dos cometidos que a partir de la creación del Consejo no fueron ya necesarias), me reuní con el Presidente Lagos para decirle que mis tareas junto a él habían llegado a término porque su interlocutor y autoridad pública en asuntos de cultura serían ahora el ministro presidente que tuvo ese Consejo. El Presidente asintió a aquello y agregó que le gustaría que permaneciera 
cerca de él —algo así como dos días por semana- para que organizara en La Moneda dos tipos de actividades culturales a ser llevadas a cabo en la propia casa de gobierno, a saber, el mencionado ciclo de Conferencias Presidenciales de Humanidades y un ciclo de Conciertos de Temporada, uno por cada estación del año, que llevaron hasta La Moneda a varios miles de pobladores de la Región Metropolitana. Recuerdo perfectamente esta frase del Presidente Lagos: "A veces el ejercicio de este cargo se pone algo fome, de manera que con esas conferencias y conciertos vamos a entretenernos un poco". Y más que nos entretuvimos, como también ocurrió con el público que asistió a ellas. El Presidente Lagos estuvo en la mayoría de las conferencias, sentado en primera fila y premunido de lápiz y papel para tomar notas.

Poniendo ahora atención a las conclusiones a que arriba Carlos Huneeus luego de su largo y minucioso recorrido de cerca de 600 páginas por los beneficios, costos, retardos, expectativas, temores, concesiones, hipocresías, frustraciones y promesas cumplidas e incumplidas de nuestra transición, resulta fácil concordar con el autor en algunas de ellas. Por ejemplo en su diagnóstico acerca del debilitamiento progresivo de nuestro sistema político y sobre el aumento de la falta de credibilidad en las instituciones, sean éstas públicas o privadas. Disminución efectiva de la pobreza, es cierto, pero aumento de las desigualdades, puesto que — si me permiten la siguiente metáfora - si ahora pueden comer pan (lo básico) muchos más de los que podían hacerlo al término del gobierno militar, esos muchos más están ahora sabiendo de las tortas sólo porque las observan a través de las vidrieras de las pastelerías en cuyo interior disfruta únicamente una minoría, bendecida muchas veces por la herencia antes que por el mérito, y que, de una manera o de otra (por ejemplo, eludiendo el pago de sus impuestos), se las arregla para mantener bien cerrada la puerta del local. Primacía de la economía sobre la política, asimismo, y no sólo en cuanto aquélla como saber de expertos, sino también como intereses dominantes que se coludieron con el poder político, tanto de un lado como del otro, en una alianza que tiene hoy escandalizada a la población del país.

Avance en la medida de lo posible podría decirse respecto de los cuatro gobiernos de la Concertación, aunque el punto es quién determinó lo que era posible, primero, y si, una vez determinado, se cubrió realmente y a buen tranco el espacio de lo posible, tanto desde un punto de vista político como económico. 
Siempre la política es en la medida de lo posible, aunque lo posible debería ser en cada gobierno no sólo una determinación a cargo de expertos. Lo posible, una vez determinado, puede ir ensanchándose paso a paso, incluso con una cierta celeridad, pero hemos tenido una tendencia a movernos poco desde un escalón al siguiente del ascenso en que nos encontramos. Siempre la democracia favorece los acuerdos, pero eso no significa que toda discrepancia tenga que ser resuelta de esa manera.

Nuestra democracia semisoberana - y si no semi, sí parcialmente soberana- tiene todavía camino que recorrer. Algunas de las reformas del gobierno de Michelle Bachelet apuntan en tal sentido, especialmente aquella que terminó con el sistema binominal y, sobre todo, el proceso ya abierto que tendría que conducirnos a una nueva constitución. "Si las reformas institucionales y los cambios de políticas no se llevan a cabo - concluye Huneeus - , se consolidará la democracia semisoberana" (497).

¿Autoflagelante Huneeus? Yo diría crítico y, desde luego, nada complaciente, lo cual no le impide destacar los avances que tuvimos con los cuatro gobiernos de la Concertación. ¿Con la mirada puesta Huneeus en la parte vacía del vaso? Clarísimamente, mas sólo para recordarnos que terminar de llenar el vaso no constituye ni un peligro ni tampoco una utopía. Ni un peligro ni una utopía, he señalado, aunque se trata de una tarea que enfrenta a intereses tanto políticos como económicos, los que en alguna medida han llegado a ser una sola y misma cosa. ¿Escéptico Huneeus? No me parece, aunque tampoco candoroso como para creer que el camino faltante estará exento de errores o que contará con una suficiente determinación propia - digamos de la centroizquierda - o que, sobre todo, no enfrentará, como de hecho lo está haciendo a partir de 2014, la oposición, bastante cerrada, de quienes perciben la amenaza que una república soberana representa para sectores conservadores que se acostumbraron a jugar con las bazas a su favor, tanto en el campo político como económico. ¿Enemigo Huneeus de "la medida de lo posible", entendida esta última como la lógica que se habría impuesto en los gobiernos posteriores a Pinochet y no únicamente en cuanto a la justicia — que cabía esperar en materia de derechos humanos-, sino también en materias políticas, económicas, culturales y sociales? Crítico, respondería yo, mas no porque esa lógica carezca de alguna validez general en el manejo y desempeño de cualquier gobierno, sino porque los cuatro primeros gobiernos de la Concertación se 
habrían quedado cortos a la hora de determinar qué era posible en cada uno de sus respectivos períodos presidenciales.

Gobernar en "la medida de lo posible" es un planteamiento tan realista como prudente, pero no lo es desaprovechar el espacio de lo posible o mensurar ese espacio por debajo de las dimensiones que realmente tiene en un momento dado. EP 